\title{
Effectiveness of Mathematics Teacher Education Training in Nigeria: An Assessment of Pre-service Mathematics Teachers' Learning Needs
}

\author{
Muhammad Alhaji Ibrahim ${ }^{1,2 *}$ (), Wun Thiam Yew ${ }^{2}$ (), Nordin Bin Abd Razak ${ }^{2}$ (C)
}

${ }^{1}$ Sule Lamido University Kafin Hausa, Jigawa State, NIGERIA

${ }^{2}$ Universiti Sains Malaysia, MALAYSIA

*Corresponding Author: hassanhadejia2003@gmail.com

Citation: Ibrahim, M. A., Yew, W. T., \& Abd Razak, N. B. (2020). Effectiveness of Mathematics Teacher Education Training in Nigeria: An Assessment of Pre-service Mathematics Teachers' Learning Needs. International Journal of Pedagogical Development and Lifelong Learning, 1(1), e02003. https://doi.org/10.30935/ijpdll/8313

\begin{abstract}
Little emphasis has been given on the pre-service mathematics teachers' learning needs on the required subject matter knowledge and skills for which they have been expected to possess at their final level of graduation, as a basis for teaching secondary school mathematics. This study employed qualitative research design, in which 30 pre-service mathematics have been interviewed on their mathematics learning needs. The finding of the study revealed that learning experiences of the training was adequate, but there is disconnection between the training curriculum and school mathematics subject matter for which the pre-service teachers have been trained to teach. The pre-service mathematics teachers have viewed lecturer of the program as non-supportive which prevent them from active learning. This suggests that the program should include school mathematics curriculum in the training to enable the pre-service mathematics teachers to acquire the subject matter knowledge for which they have been trained to teach. Lecturers of the program should change their attitude and behavior which might have adverse effect on pre-service mathematics teachers' learning.
\end{abstract}

Keywords: mathematics, teacher education, pre-service teachers, learning needs

Received: 23 Apr. $2020 \bullet$ Accepted: 30 May 2020

\section{INTRODUCTION}

Mathematics teacher education training is the same as any other teacher education program provided by Nigerian teacher training institutions. The program was specifically designed to provide mathematics training to both pre-service and in-service teachers, and equip them with adequate subject matter knowledge and skills capable of developing their efficiency and motivational skills for effective classroom instruction. The training was expected to groom pre-service mathematics teachers with adequate subject matter knowledge of secondary school mathematics which will enable them to shoulder the responsibilities repose on them (Ibrahim et al. 2018, 2020; NUC, 2019).

The goal of mathematics teacher education training in the national policy on teacher education is to (NUC, 2019, p. 8):

1. Enable students to acquire the various concepts, principles, theories and laws of mathematics;

2. Enable students to acquire necessary teaching skills and other aspects of methodology of teaching mathematics;

3. Help students to become effective classroom teacher;

4. Acquire the ethics of teaching as a profession;
5. Become professional mathematics teacher;

6. Disseminate information in mathematics to the society;

7. Develop positive values and attitudes for efficient discharge of their duty as teachers.

Similarly, national policy on teacher education training has emphasized on the objectives of providing quality teacher education training that "no education system may rise above the quality of its teachers, teacher education shall continue to be given major emphasis in all educational planning and national development" (NPE, 2004, p. 39). Therefore, mathematics teacher education training should gear toward the attainment of national policy objectives of the program. Ntuli et al. (2016) posit that for teacher education program to achieve their set objectives there is need for the training to emphasize on the global objectives of education and contents that infuse $21^{\text {st }}$ century skills and pedagogical knowledge which will facilitate change in attitude, knowledge and skills. This could enable teachers to possess adequate subject matter knowledge and skills capable of influencing students' behavior. The global objectives of teacher education have been summarized as follows (Nakhat \& Tazyeen, 2016, p. 3): 
to train the mind for overall development of personality and Character-Building, to make a man, a human being, to train for skilled personal and the cooperative, to generate in people the consciousness of the environment, to inculcate in children the habits of prudence, economy and self-improvement, to equip an individual with knowledge a wisdom both, to enhance quality of life of an individual, to develop positive attitudes towards life and being, to acquaint the people with deride level of knowledge information, to promote universally shared values in children, to improve, their ability to think and equip them with specialized skills useful in different areas of trade, commerce, industries and services.

Despite the statement of objectives of the training and national policy objectives of grooming quality school mathematics teachers who will shoulder the responsibilities of providing quality education at secondary school level. There is course of alarm over the quality of recently graduated pre-service mathematics teachers. The level of knowledge of the subject matter display by some mathematics teachers is more of comparable to the understanding of pupils for which they have been train to teach to the extent that the teachers cannot be relied upon to raised the quality of school (Musa, 2011; Obioma, 2005). A large body of researches has shown that some school mathematics teachers have poor level of knowledge of school mathematics subject matter to the extent that many stakeholders doubt about the process they obtained the certificate they possess (Aluede \& Idogho, 2014; Anaduaka \& Okafor, 2013; Omorogbe \& Ewasnsiha, 2013; Yaro, 2019).

However, some educational researchers have argued that the lack of subject matter knowledge demonstrated by some school mathematics teachers was associated with inability of teacher training institution to connect the training curriculum with school mathematics subject matter for which the pre-service teachers have been train to teacher (Ajeyalami, 2005; Okebukola, 2005). This may possible be the main reason that inhibit the school mathematics teachers to possess adequate subject matter knowledge of school mathematics during their preservice training. The expectation of the society on mathematics teacher education training is for pre-service teachers to possess adequate subject matter knowledge, pedagogical skills and competency, which will enable them to influence their students and raised the quality of school. Unfortunately, the current training "is not in a good phase as regard its product in term of marketability, teachers' quality, subject mastery, professional competent, pedagogical acumen among others" (Adedeji, 2018, p. 1).

Reference to this, the researcher deems it necessary to explore preservice mathematics teachers' learning needs, to find out whether it has profound effect on objectives of the training. In this study, the term mathematics learning needs of pre-service mathematics teachers was used as a measure of assessing the gap between what the training have being equipping pre-service mathematics teachers with and actual knowledge and skills they might require to be qualify as effective school mathematics teachers. Students' learning needs have been regarded as "the gap between the learner's current level of knowledge and skills, and the level of knowledge and skills required to perform a task or a set of tasks" (Ryan, 2014, p. 1).

Objective of the study: The objective of this study is to explore mathematics learning needs of pre-service mathematics teachers.
Research question: The research will provide answer to this question.

What are the mathematics learning needs of pre-service mathematics teachers?

\section{METHODOLOGY}

The study employed qualitative method in which interview protocol was used as the main instrument for data collection. A purposive sampling technique was used to select 30 pre-service mathematics teachers at as sample of the study. The number of preservice mathematics teachers is enough as Creswell (1998) suggested for 20-30 respondent in qualitative research question. A purposive sampling technique has been identified as the most effective nonprobability sampling technique when a researcher is interested to study certain cultural domain with expertise (Tongo, 2007). He further describes the process of purposive sample selection as a deliberate choice due to certain qualities that informant possesses (Tongco, 2007). Moreover, Black (2010) has describes purposive sampling as a:

Non-probability sampling method and it occurs when elements selected for the sample are chosen by the judgment of the researcher. Researchers often believe that they can obtain a representative sample by using a sound judgment, which will result in saving time and money (p. 1).

\section{FINDINGS}

The study aims to explore mathematics learning needs of preservice mathematics teachers. The discussion of pre-service mathematics teachers' learning needs focuses on the four themes generated from the analysis of information obtained from interview protocol. The four themes generated are; learning experience, difficulties encountered, relationship between the program curriculum and school mathematics curricular, and how the program should be run.

\section{Learning Experience}

This sub-section of pre-service mathematics teachers' learning needs is concern with learning experience of pre-service mathematics teachers from year one to three. Different information was gathered on how the pre-service mathematics teachers have experience learning the program from year one to three. The perspectives of pre-service mathematics teachers on their learning experience were summarize in Table 1.

Table 1. Mathematics learning experience of pre-service teachers

\begin{tabular}{ll}
\hline Learning Experience & Pre-service Mathematics Teachers \\
\hline $\begin{array}{l}\text { Very essential in } \\
\text { learning }\end{array}$ & PMT2, PMT4, PMT6, PMT7, PMT9, PMT14, \\
\hline PMT17, PMT18, PMT21, PMT22, PMT25, PMT29
\end{tabular}

Table 1 presents mathematics learning experiences of pre-service mathematics teachers from year one to three. The table shows that PMTs 2, 4, 6, 7, 14, 17, 18, 21, 22, 25 and 29 have views their learning 
experience as very essential, which enable them to acquire a lot of thing. The pre-service teachers accentuate their opinions on the important of their experiences in learning mathematics teacher education as,

My first year experience was very important, because I gained a lot of things which I do not expect to happen. The experiences enable me to learn a lot of things which is not easily to mention, like trigonometry identities i.e. Sin and Tan (PMT 2)

My learning experience is different from previous years, in which I have been battling with many processes of learning, but this year I have learn a lot like research (PMT 14).

My third year learning experience was very significant to my study, because I learn so many things which enable me to develop skills from my lecturers, especially the methodology of teaching, knowledge of writing project and how to evaluate the students when I go for teaching practice etc. (PMT 21).

It appears that the pre-service teachers appreciate their learning experiences in the program. This provides the evidence the training is exposing the pre-service teachers into difference learning activities, which will enable them to acquire knowledge and skills. The pre-service teachers noted that the training have provides them with opportunities to learn knowledge and skills of teaching mathematics. Such learning experience might possibly enable the pre-service teachers to acquire the required subject matter, and facilitate the achievement of the set objectives.

It appears that PMTs 12, 16, 23, 24 and 28 have similar views on their learning experience, in which they posits the experience provides them with opportunity to developed their learning skills. They clarify further that,

My learning experience in the second year of the program is widening because of the challenges I faced. All the eight courses I registered in level one is only three courses that are mathematics. Now the courses I took are easy and very simple (PMT 16).

Before, my thinking is that as I proceed to level 300 the difficulty will be reducing, but now what I'm experiencing in third year is not easy. I can describe it as level of graduation. But the experiences develop our skills (PMT 23).

From the perspectives of PMTs 16 and 23 on their learning experience from year one to three shows that the training has enable the pre-service teachers to develop their cognitive ability. This has highlighted on how the training was able to transform pre-service teachers' learning ability from simple to complex. Such transformation might enable the pre-service teachers to simplify any complex problem that might be presented to them into simpler. And the pre-service teachers might possibly be able to simplify difficult topics of school mathematics subject into very simple. This might provide their students with opportunity to actively participate in the problem solving.

Moreover, the information from the perspectives of PMTs 20, 26, 27 and 30 on their learning experience in mathematics teacher education program shows that their experiences in the program enable them to explore their learning environment. They explain further that:
The learning experiences in the program enable me to visit some of the facilities in the university such as e-library. This has helped me in learning computer (PMT 20)

I can describe my learning experience in this year as a something different, because of some changes such as environment and other physical factors that influence my learning in the campus. Awareness of some course tutors helps my learning tremendously and gave me good hope (PMT 27).

The perspectives of PMTs 20 and 27 shed light on how the program has exposed the pre-service teachers into different learning activities which enable them to be acquainted with the learning environment. This has enabled the pre-service teachers to actively engage in the training and influence their learning. Such learning experience suggests that for mathematics teacher education program to actively engage the pre-service teachers, the training must expose them to the learning environment and become acquainted with the facilities. This could enable them to actively engage and influence their performance.

\section{Difficulties Encountered}

This sub-section of pre-service mathematics teachers' learning needs is concern with some of the learning difficulties in which preservice mathematics teachers have encountered from year one to three, in learning the program. Different information was gathered on the area of learning difficulty. The perspectives of pre-service mathematics teachers on their learning difficulties were summarize in Table 2.

Table 2. Pre-service Mathematics Teachers' Learning Difficulties

\begin{tabular}{ll}
\hline Learning Difficulties & Pre-service Mathematics Teachers \\
\hline $\begin{array}{l}\text { Lack of supportive } \\
\text { lecturers }\end{array}$ & $\begin{array}{l}\text { PMT1, PMT3, PMT11, PMT13, PMT19, PMT20, } \\
\text { PMT25, PMT28 }\end{array}$ \\
\hline $\begin{array}{l}\text { Lack of conducive } \\
\text { classroom }\end{array}$ & PMT2, PMT4, PMT8, PMT18, PMT22, \\
\hline $\begin{array}{l}\text { Difficult courses } \\
\text { PMT5, PMT9, PMT10, PMT12, PMT14, PMT15, } \\
\text { PMTk of facilities }\end{array}$ & PMT6, PMT7, PMT26, PMT27 \\
\hline $\begin{array}{l}\text { Poor academic } \\
\text { performance }\end{array}$ & PMT17, PMT24, PMT30 \\
\hline
\end{tabular}

Table 2 presents pre-service mathematics teachers' learning difficulties from year one to three. The table shows that PMTs 1, 3, 11, 13, 19, 20, 25 and 28 have views lack of supportive lecturers in the program, as major difficulty they encountered which affect their learning in the program. They explain further that the lack of supportive lecturers who will attend and listen to their problem has seriously affected their engagement in the program. They say,

"The difficulty is from the lecturers, they are not as well as we want and sometimes if we don't understand the lesson they will not go through the question and do it again for us to understand better" (PMT 1).

“The difficulty I experience during second year, for me, it's hardly to forward your complain to the department and get meaningful response” (PMT 11).

"The difficulty is the lack of lecturers in the program" (PMT 25).

The evidence from the perspectives of PMTs 1, 11and 25 shows that, how difficult it's for the pre-service teachers to actively engage in 
the lesson. It is because lecturers of the program are not supportive and chances of getting positive response from the department were little. This lack of support from both lecturers and administrative of their department might possibly affect students learning, which may possibly result into poor academic performance. Research literature has shown that students' academic achievement and social development are influence by teachers and student's positive relationship (RimmKaufman \& Sandilos, 2013). The more students they have positive relationship and support from their teachers, the more they attain higher level of achievement (Rimm-Kaufman \& Sandilos, 2013).

According to PMTs 2, 4, 8, 18 and 22, the difficulty they encountered in learning mathematics teacher education is the lack of conducive classroom which will enable them to actively engage in the classroom instruction. They further noted that the number of students in the class has affected their listening, because of the excessive noise in the class. They say,

"The difficulty I face in this program is that most students are not listening when lecturer is delivering the lesson, because they are making noise in the class. Because of that, I take like a week before I understand the lesson" (PMT 2).

"The difficulty is the lack of enough classrooms to accommodate all education students and listened to the lecturer" (PMT 18).

"My learning difficulty is the lack of availability of lecture room" (PMT 22).

Furthermore, to PMTs 6, 7, 26 and 27, the lack of facilities in the institution which will enable them to finish their registration within the stipulated period is the encountered difficulty in learning mathematics teacher education program. They posit that the lack of facilities and appropriate arrangement for the registration, which will enable the pre-service teachers to finish their registration in time, has significantly affects their engagement to the academics activities. They clarify their views that,

"The first difficulty I encountered is at the time of registration, there is a lot of conjunction during the registration" (PMT 6).

"The difficulty is that, during the registration the students including me find it difficult due to the university arrangement" (PMT 26)

These pre-service teachers' views suggest that the university must provide enabling environment which will facilitate registration and enable pre-service teachers to finish their course registration in time. By doing so the pre-service teachers might possibly have enough time to prepare in advance before the commencement of academic activities. This may enable the pre-service teachers to actively engage in the program.

According to PMTs 17, 24 and 30, the difficulty they encountered during learning mathematics teacher education is their poor academic performance. The pre-service teachers described their poor academic performance in the program as a destiny in which no one can escape. They says,

"I got six carryover and I have very low grade" (PMT 17).
"Every human being has his own destiny and individual difference, and there are some difficulties no one could progress in life without going through, like low performance academically" (PMT 24).

Relationship between the Program Curriculum and School Mathematics Curricular

This sub-section of pre-service mathematics teachers' learning needs is concern with perspectives of pre-service mathematics teachers on the relationship between their program curriculum contents and school mathematics subject matter. Different information was gathered on the relationship between the two curriculums. The perspectives of pre-service mathematics teachers on the relationship between mathematics teacher education program curriculum and school mathematics curricular was summarize in Table 3.

Table 3. Relationship between mathematics education curriculum and school mathematics curricular

\begin{tabular}{ll}
$\begin{array}{l}\text { Relationship Between } \\
\text { the two Curriculums }\end{array}$ & Pre-service Mathematics Teachers \\
\hline Partially related & PMT1, PMT3, PMT9, PMT10, PMT12, PMT21, \\
& PMT24, PMT26, PMT28, PMT29. \\
\hline Related & PMT2, PMT4, PMT5, PMT6, PMT7, PMT8, \\
& PMT11, PMT14, PMT15, PMT16, PMT18, \\
& PMT22, PMT25, PMT27. \\
\hline Different & PMT13, PMT17, PMT19, PMT20, PMT23, \\
& PMT30. \\
\hline
\end{tabular}

Table 3 presents pre-service mathematics teachers' perspectives on the relationship between their program curriculum contents and school mathematics subject matter. The table shows that PMTs 1, 3, 9, 10, 12, $21,24,26,28$ and 29 have perceived their program curriculum contents was partially related with school mathematics subject matter for which they have been train to teach after graduation. They accentuate their perspectives on the relationship between the two curriculums in which they said,

"In this case I use to look over on the similarities and little difference on my program with school mathematics. There are some topics that are related with school mathematics" (PMT 9).

"There are some differences though; there are lots of similarities in most topics and objectives" (PMT 24).

These perspectives of PMTs 9 and 24 reveal that there is some discrepancy between mathematics teacher education program curriculum and school mathematics subject matter for which preservice teachers have been train to teach after graduation. These differences in the curriculum might affect pre-service teachers' level of knowledge of the subject matter, for which they have been trained to teach and subsequently may perhaps affect the achievement of the set objectives of the program.

According to PMTs 2, 4, 5, 6, 7, 8, 11, 14, 15, 16, 18, 22, 25 and 27, their program curriculum was related to school mathematics subject matter. They further noted that the curriculums are related in terms of contents and objectives. They clarify their perspectives on the relationship as,

"My program curriculum is almost about school mathematics curriculum. Therefore, the two curriculums are related with each other through contents and objectives" (PMT 6) 
"I relate the program with school mathematics curriculum based on their 9-year Basic National Policy on education (NPE) and New 9 year Basic National Educational Research Development Council. The curriculums are related based on their contents, objectives, introduction and evaluation" (PMT $11)$.

"The curriculums are highly related in terms of contents" (PMT 27).

The above perspectives of PMTs 6, 11 and 27 indicates that the program was able to equip pre-service teachers with require subject matter knowledge, which could enable them to possess adequate subject matter knowledge of the curriculum for which they have been train to teach after graduation. The possession of the subject matter might enable the pre-service teachers to sufficiently and effectively teach school mathematics. This may raise the quality and standard of mathematics teacher education program.

However, PMTs 13, 17, 19, 20, 23 and 30 posited that their program curriculum was different from school mathematics subject matter for which they have been trained to teach after graduation. They accentuate their views on the difference between the two curriculums. They said,

"Relating my program curriculum with school mathematics is something incomparable, because there are so many changes and difference between the two curriculums" (PMT 13).

"My program curriculum is different from school curriculum, because what we have been taught is different from what we learn in secondary school" (PMT, 23).

The plausible explanation of these views of PMTs 13 and 23 is that the pre-service teachers were able to highlight some of the discrepancies between their program curriculum and school mathematics subject matter for which they have been train to teach after graduation. This indicates that there is possibility that the preservice teachers might not necessary possess the require subject matter knowledge, which will enable them to effectively teach school mathematics after graduation. It is because their program curriculum does not include school mathematics subject matter for which they were expected to teach after graduation.

Consequently, a fair conclusion can be drawn based on the opinions of pre-service mathematics teachers on the relationship between the two curriculums. More than half of the pre-service teachers had posits their program curriculum was related with school mathematics subject matter in terms of objectives of the study, contents and so on. Therefore, mathematics teacher education program curriculum contents were related with school mathematics subject matter for which pre-service teachers have been trained to teach after graduation. This suggests that the relationship between the two curriculums may enable the pre-service teachers to possess adequate subject matter knowledge of school mathematics.

\section{How the Program should Run}

This sub-section of pre-service mathematics teachers' learning needs is concern with perspectives of pre-service teachers on how mathematics teacher education program should be run, based on their learning experience and encountered difficulty. Different information was gathered on how mathematics teacher education should be run in order to achieve the set objectives. The perspectives of pre-service mathematics teachers on how mathematics teacher education program should be run were summarized in Table 4 .

Table 4. How mathematics teacher education program should be run

\begin{tabular}{ll}
\hline $\begin{array}{l}\text { How the Program } \\
\text { should be run }\end{array}$ & Pre-service Mathematics Teachers \\
\hline Supportive lecturers & PMT1, PMT2, PMT4, PMT5, PMT6, PMT7, \\
& $\begin{array}{l}\text { PMT10, PMT11, PMT13, PMT20, PMT22, } \\
\text { PMT24, PMT25 }\end{array}$ \\
\hline
\end{tabular}

Mathematics courses to be PMT3, PMT29, PMT30

taught at faculty

Include modern $\quad$ PMT9, PMT14, PMT15, PMT16, PMT18,
mathematics curriculum PMT19, PMT21, PMT26, PMT28

(geometry, algebraic

process and trigonometry)

Educational courses to be PMT8, PMT12 PMT17, PMT23, PMT27 students centered

Table 4 presents pre-service mathematics teachers' perspectives on how mathematics teacher education program should be run. The table shows that PMTs 1, 2, 4, 5, 6, 7, 10, 11, 13, 20, 22, 24 and 25 have suggested that if lecturers of the program encourage their students through motivation and advice, the objectives of the program could be achieved. The pre-service teachers have views lecturers' support as a learning factor which has direct effect on their engagement. They clarify their views on how the program should run.

"What I want is lecturers should avoid disgracing students. In fact, I want the lecturers to encourage the students so that good atmosphere of teaching and learning will take place" (PMT 6).

"The lecturers should encourage students by motivation and good advice" (PMT 11).

"Through encouragement and handling the courses to appropriate and well qualify lecturer" (PMT 24).

To PMTs 3, 29 and 30, if the program will be run as independent program (i.e. mathematics courses to be taught at the department, by lecturers of the department), the set objectives of the program could be achieved. They further explain that mathematics courses should be separated from faculty of science and handle by education lecturers. This will enable pre-service teachers to possess adequate subject matter knowledge. They said,

"There is little change that is needed, to make mathematics education students separated from science, while lecturers of education to teach mathematics courses. This may give the students chance to understand the subject" (PMT 3)

"Mathematics courses should be taught by education lecturers like other science course they were doing" (PMT 30).

The suggestion of PMTs 3 and 30 on how the program should be run shows that the pre-service teachers were concern and appreciate the training they were receiving from mathematics education department lecturers. The suggestion indicates that lecturers of the department are supportive and if they were to teach mathematics courses, there might be a possibility for pre-service teachers to be equipped with school mathematics subject matter. This may facilitate the achievement of the set objectives of the program, since the pre- 
service teachers are being train to teach school mathematics after graduation.

Moreover, PMTs 9, 14, 15, 16, 18, 19, 21, 26 and 28 have suggested that if the program will include modern mathematics curriculum in the training the objective could be achieved. They posited that if modern mathematics curriculum contents were included in the program, the pre-service teachers might have the opportunity to learn about school mathematics subject matter for which they have been trained to teach. They further explain that,

"The program should be run by introducing modern mathematics curriculum contents to enable us acquire knowledge of secondary school mathematics" (PMT 9).

"My opinion on how the program should be run is based on my experience. The program should be run base on secondary curriculum and design to be different from what I encountered in my first year" (PMT 16).

"The curriculum contents of the program to be up to date and relevant to secondary school mathematics curriculum" (PMT 26).

The perspectives of pre-service teachers suggested that the program should be run in such a way that it will enable them to acquire school mathematics subject matter knowledge. The pre-service teachers emphasize on modern mathematics curriculum as the contents area which will enable them to acquire school mathematics subject matter knowledge and facilitate the achievement of the set objectives of the program. This implies that if the program could include modern mathematics curriculum in the training the pre-service teachers might possibly possess the require subject matter knowledge, since they have the zeal and willingness to learn the program.

Similarly, PMTs $8,12,17,23$ and 27 have suggested that the program should be run by including additional courses (i.e. psychology, and mathematics for all level) which will enable pre-service teachers to acquire adequate subject matter knowledge and skills. The courses must be students centered to ensure all the pre-service teachers were participated in the class. PMT 17 says, "The program should be run by including new course (i.e. psychology and mathematics from level 1 to 4), based on like students centered to ensure that everyone participate in class".

\section{DISCUSSION}

The assessment of pre-service mathematics teachers' learning needs has revealed that majority of the pre-service teachers have described their learning experiences as adequate and interesting which provide them with many learning opportunities. This provides the evidence that the training was designed to expose pre-service teachers to the role of school teachers as stipulated in the NUC BMAS (NUC, 2017). This is because the pre-service teachers have appreciated the knowledge and skills they acquired during the training. The analysis of mathematics learning needs of pre-service teachers has shown that the pre-service teachers had suggested different ways and techniques on how the program should be run, to enable them to possess the required subject matter knowledge and skills. Among the technique and contents areas they suggest being included in the program are supportive lecturers, curriculum relevant to school mathematics subject matter, modern instructional technology, mathematics courses to be taught at faculty etc. This indicates how the pre-service teachers were concerned about their learning and teaching needs which will enable them to acquire appropriate teaching skills and effectively teach school mathematics.

Inability of the program to provide and satisfied pre-service teachers with these learning needs might impede them to possess appropriate teaching skills and subsequently might result to non achievement of the set objectives. Individual are motivated to function effectively when their needs are satisfied (Ibrahim et al., 2018). Previous study has shown that individuals are motivated to function effectively and provide better result when their basic needs are provided and satisfied at the required time (Maslow, 1954). The plausible explanation of these perspectives of pre-service teachers on their mathematics learning needs is that the pre-service teachers have views supportive lecturers as one of the learning factors that could influence them to actively engage in the learning. Tanveer et al. (2012) have found that students were motivated to learn efficiently when teachers promote active participation, lesson collaboration, de-emphasizing grade and their positive emotion. This was also applied to pre-service teachers, if lecturers of the program could support pre-service teachers through positive emotion, collaborative learning and de-emphasize on the grad, the pre-service teachers will be influenced to learn and academically achieved. Previous studies have shown that students' performance, taking responsibility and showing interest in the class was strongly influence by motivation (Legault et al., 2006; Singh et al., 2002).

\section{CONCLUSION}

The objectives of this study are to explore mathematics learning needs of pre-service mathematics teachers, whether it has profound effective on the achievement of the set objectives of the training. The findings suggest that the learning experiences of the training were adequate, as majority of the pre-service teachers have appreciated the experience for which they have been exposed to. The finding revealed a discrepancy between the program curriculum and school mathematics curricular for which the pre-service mathematics teachers have been trained to teach. This suggest that the objectives of the training may not possibly be achieve as set, since there is disconnection between the training curriculum and school mathematics subject matter for which the pre-service mathematics teacher have been trained to teach.

\section{REFERENCES}

Adedeji, T. (2018). Revitalizing Mathematics education preparation in Nigeria for national development: An innovative view. International Electronic Journal of Mathematics Education, 13(3), 315-320. https://doi.org/10.12973/iejme/3923

Ajeyalemi, D. (2005). Challenges of teacher education for secondary schools in Nigeria. Paper presented at 2 -day National Workshop on the Counting Crisis of Secondary School Education in Nigeria: Confronting Old and New Challenges, Abuja, Nigeria, September 13-14. 
Aluede, O., \& Idogho, P. O. (2014). Refocusing Teacher Education for Nigeria's National Development: Issues and Policies for Implementation. International Studies in Educational Administration (Commonwealth Council for Educational Administration \& Management (CCEAM)), 42(3), 60.

Anaduaka, U. S., \& Okafor, C. F. (2013). Poor performance of Nigerian students in mathematics in senior secondary certificate examination (SSCE): What is not working? Journal of Research in National Development, 11(2), 1-5. https://doi.org/10.12691/ education-1-7-5

Black, K. (2010). Business Statistics: Contemporary Decision Making $\left(6^{\text {th }}\right.$ ed.). John Wiley \& Sons.

Creswell, J. W., \& Clark, V. L. P. (2017). Designing and conducting mixed methods research. Sage publications.

Ferreira, A., \& Santoso, A. (2008). Do students' perceptions matter? A study of the effect of students' perceptions on academic performance. Accounting \& Finance, 48(2), 209-231. https://doi.org/10.1111/j.1467-629X.2007.00239.x

Ibrahim M. A, Wun T. Y., \& Nordin A. R. (2020). Mathematics Teacher Education training for Quality School Teachers; An Assessment of Mathematics Teaching Needs of Pre-Service Teachers'. International Journal of Psychosocial Rehabilitation, 24(4), 38-47. https://doi.org/10.37200/IJPR/V24I4/PR201361

Ibrahim, M. A., Wun, T. Y., \& Nordin, A. R. (2018). Mathematics Teacher Education in Nigeria: An Evaluation Model. Paper Presented at International Postgraduate Conference on Research in Education, Universiti Sains Malaysia, Penang, 16-18 August.

Kaur, M. (2017). To Recognise, Realise and Differentiate the Learning Needs of Students. Pertanika Journal of Social Sciences \& Humanities, 25(2), 503-510.

Legault, L., Green-Demers, I., \& Pelletier, L. (2006). Why do high school students lack motivation in the classroom? Toward an understanding of academic motivation and the role of social support. Journal of educational psychology, 98(3), 567. https://doi.org/10.1037/0022-0663.98.3.567

Maslow, A. H. (1954). The instinctoid nature of basic needs. Journal of Personality, 22, 326-347. https://doi.org/10.1111/j.1467-6494.1954. tb01136.x

Musa, M. (2011). Teacher Professional Support and Mentoring as Viable alternative to the falling Standards of Education: A case study with Mathematics. Paper presented at Annual speech and prize day of A. B. U. Staff School Zaria, Kaduna, Nigeria.
Nakhat, N., \& Tazyeen, B. (2016). Global Objectives of quality Education, Possibilities and Challenges. IOSR Journal of Humanities and Social Science (IOSR-JHSS) 21(2), 16-24. https://doi.org/10.9790/0837-21241624

Nigerian University Commission. (2019). Manual for accreditation procedures of academic programs in Nigerian university (MAP). Retrieved from http://nuc.edu.ng

Ntuli, E., Nyarambi, A., Agamba, J. J., \& Ntuli, V. (2018). Globalization and Teacher Education: Challenges and Solutions to 21st Century Content Preparation and Pedagogy in Africa. In Teacher Training and Professional Development: Concepts, Methodologies, Tools, and Applications (pp. 1443-1462). IGI Global. https://doi.org/10.4018/978-1-5225-5631-2

Obioma, G. O. (2005). Popularizing mathematical science for technological Development. In S. O. Ale \& L. O. Adetula (Ed.). Reflective and intellective Positive papers on mathematics education. Abuja: NMC.

Omorogbe, E., \& Ewansiha, J. C. (2013). The challenge of effective science teaching in Nigerian secondary schools. Academic Journal of Interdisciplinary Studies, 2(7), 181. https://doi.org/10.36941/ajis

Rimm-Kaufman, S., \& Sandilos, L. (2013). Improving students relationships with teachers to provide essential supports for learning: Positive relationships can also help a student develop socially. American Psychological Association. Retrieved from https://www.apa.org/education/k12/relationships\#: :text=Yes\%2 C\%20positive\%20teacher\%2Dstudent\%20relationships,et\%20al.\%2 C\%202004).

Singh, K., Granville, M., \& Dika, S. (2002). Mathematics and science achievement: Effects of motivation, interest, and academic engagement. The Journal of Educational Research, 95(6), 323-332. https://doi.org/10.1080/00220670209596607

Tanveer, M. A., Shabbir, M. F., Ammar, M., Dolla, S. I., \& Aslam, H. D. (2012). Influence of Teacher on Student'Learning Motivation in Management Sciences Studies. American Journal of Scientific Research, 67(1), 76-87. https://doi.org/10.29333/ejmste/94571

Tongco, M. D. C. (2007). Purposive sampling as a tool for informant selection. Ethnobotany Research and applications, 5, 147-158. https://doi.org/10.17348/era.5.0.147-158

Umar, Y. (2019). STEM Education as a Catalyst for National Development: Problems and Prospects in Nigeria. International Learning Science and Mathematics Journal, (14), 48-59. 